\title{
Digging for DNA at depth: rapid universal metabarcoding surveys (RUMS) as a tool to detect coral reef biodiversity across a depth gradient
}

\author{
Joseph D DiBattista ${ }^{\text {Corresp., }}$ 1,2 ， James D Reimer ${ }^{3,4}$, Michael Stat ${ }^{1,5}$, Giovanni D Masucci ${ }^{3}$, Piera Biondi ${ }^{3}$, \\ Maarten De Brauwer ${ }^{1}$, Michael Bunce ${ }^{1}$ \\ ${ }^{1}$ Trace and Environmental DNA (TrEnD) laboratory, School of Molecular and Life Sciences, Curtin University of Technology, Perth, Western Australia, \\ Australia \\ 2 Australian Museum Research Institute, Australian Museum, Sydney, New South Wales, Australia \\ 3 Graduate School of Engineering and Science, University of the Ryukyus, Okinawa, Japan \\ 4 Tropical Biosphere Research Center, University of the Ryukyus, Okinawa, Japan \\ 5 Department of Biological Sciences, Macquarie University, North Ryde, New South Wales, Australia \\ Corresponding Author: Joseph D DiBattista \\ Email address: Joseph.DiBattista@austmus.gov.au
}

Background. Effective biodiversity monitoring is fundamental in tracking changes in ecosystems as it relates to commercial, recreational, and conservation interests. Current approaches to survey coral reef ecosystems center on the use of indicator species and repeat surveying at specific sites. However, such approaches are often limited by the narrow snapshot of total marine biodiversity that they describe and are thus hindered in their ability to contribute to holistic ecosystem-based monitoring. In tandem, environmental DNA (eDNA) and next-generation sequencing (NGS) metabarcoding methods provide a new opportunity to rapidly assess the presence of a broad spectrum of eukaryotic organisms within our oceans, ranging from microbes to macrofauna.

Methods. We here investigate the potential for rapid universal metabarcoding surveys (RUMS) of eDNA in sediment samples to provide snapshots of eukaryotic subtropical biodiversity along a depth gradient at two coral reefs in Okinawa, Japan based on 18S rRNA.

Results. Using 18S rRNA metabarcoding, we found that there were significant separations in eukaryotic community assemblages (at the family-level) detected in sediments when compared across different depths ranging from 10 to 40 meters $(p=0.001)$. Significant depth zonation was observed across OTUs assigned to the class Demospongiae (sponges), the most diverse class (contributing $81 \%$ of species) within the phylum Porifera; the oldest metazoan phylum on the planet. However, zonation was not observed across the class Anthozoa (i.e. anemones, stony corals, soft corals, and octocorals), suggesting that the former may serve as a better source of indicator species based on sampling over fine spatial scales and this universal assay. Furthermore, despite their abundance on the examined coral reefs, we did not detect any octocoral DNA, which may be due to low cellular shedding rates, assay sensitivities, or primer biases.

Discussion. Overall, our pilot study demonstrates the importance of exploring depth effects in eDNA and suggest that RUMS may be applied to provide a baseline of information on eukaryotic marine taxa at coastal sites of economic and conservation importance. 


\section{Digging for DNA at depth: rapid universal}

2 metabarcoding surveys (RUMS) as a tool to detect

3 coral reef biodiversity across a depth gradient

4

5

Joseph D. DiBattista ${ }^{1,2^{*}}$, James D. Reimer ${ }^{3,4}$, Michael Stat ${ }^{1,5}$, Giovanni D. Masucci ${ }^{3}$, Piera

Biondi $^{3}$, Maarten De Brauwer ${ }^{1}$, Michael Bunce ${ }^{1}$

7

$8{ }^{1}$ Trace and Environmental DNA (TrEnD) laboratory, School of Molecular and Life Sciences,

9 Curtin University, Perth, WA, Australia

$10{ }^{2}$ Australian Museum Research Institute, Australian Museum, Sydney, NSW, Australia

$11{ }^{3}$ Graduate School of Engineering and Science, University of the Ryukyus, Okinawa, Japan

$12{ }^{4}$ Tropical Biosphere Research Center, University of the Ryukyus, Okinawa, Japan

13 5epartment of Biological Sciences, Macquarie University, North Ryde, NSW, Australia

14

15 Corresponding Author:

16 Joseph David DiBattista ${ }^{1}$

171 William Street, Sydney, NSW, 2010, Australia

18 Email address: josephdibattista@gmail.com

19

20

21

22

23

24

25

26

27

28

29

30

31

32

33

34

35

36 


\section{ABSTRACT}

38

39

40

41

42

43

44

45

46

47

48

49

50

51

52

53

54

55

56

57

58

59

60

61

62

63

64

65

66

67

68

69

70

71

72
Background. Effective biodiversity monitoring is fundamental in tracking changes in ecosystems as it relates to commercial, recreational, and conservation interests. Current approaches to survey coral reef ecosystems center on the use of indicator species and repeat surveying at specific sites. However, such approaches are often limited by the narrow snapshot of total marine biodiversity that they describe and are thus hindered in their ability to contribute to holistic ecosystem-based monitoring. In tandem, environmental DNA (eDNA) and nextgeneration sequencing (NGS) metabarcoding methods provide a new opportunity to rapidly assess the presence of a broad spectrum of eukaryotic organisms within our oceans, ranging from microbes to macrofauna.

Methods. We here investigate the potential for rapid universal metabarcoding surveys (RUMS) of eDNA in sediment samples to provide snapshots of eukaryotic subtropical biodiversity along a depth gradient at two coral reefs in Okinawa, Japan based on 18S rRNA.

Results. Using 18S rRNA metabarcoding, we found that there were significant separations in eukaryotic community assemblages (at the family-level) detected in sediments when compared across different depths ranging from 10 to 40 meters $(p=0.001)$. Significant depth zonation was observed across OTUs assigned to the class Demospongiae (sponges), the most diverse class (contributing $81 \%$ of species) within the phylum Porifera; the oldest metazoan phylum on the planet. However, zonation was not observed across the class Anthozoa (i.e. anemones, stony corals, soft corals, and octocorals), suggesting that the former may serve as a better source of indicator species based on sampling over fine spatial scales and this universal assay. Furthermore, despite their abundance on the examined coral reefs, we did not detect any octocoral DNA, which may be due to low cellular shedding rates, assay sensitivities, or primer biases.

Discussion. Overall, our pilot study demonstrates the importance of exploring depth effects in eDNA and suggest that RUMS may be applied to provide a baseline of information on eukaryotic marine taxa at coastal sites of economic and conservation importance. 


\section{INTRODUCTION}

74 In coral reef ecosystems, shifts in community structure often occur at small spatial scales. For

75 example, marine taxa may be restricted to specific reef zones (e.g. lagoon, reef crest, fore reef;

76 Menza, Kendall \& Hile, 2008) or separated by depth (Friedlander \& Parrish, 1998; Kahng \&

77 Kelley, 2007; Brokovich et al., 2008), which represents the steepest environmental gradient on

78 coral reefs. Increasing depth is associated with decreases in light irradiance, wave action,

79 nutrients, and temperature variation (Lesser, Slattery \& Leichter, 2009a; Slattery et al., 2011).

80 Reef-building corals and other anthozoans in particular show pronounced variation in

81 morphology (Nir et al., 2011) and in the composition of their symbiotic Symbiodiniaceae (Lesser

82 et al., 2009b; Bongaerts et al., 2013; Kamezaki et al., 2013) across depth gradients. Coral reef

83 fish communities similarly exhibit changes in species richness and composition with depth

84 (Brokovich et al., 2008; Bejarano, Appeldoorn \& Nemeth, 2014).

85 Until recently, spatial surveys of marine biodiversity have primarily focused on megafauna

86 and macrofauna (Gaston, 2000; Tittensor et al., 2010) or microfauna (e.g. Sunagawa et al., 2015;

87 Soliman et al., 2017), rather than meiofauna (the polyphyletic group of organisms that fall

88 somewhere in between) (Lambshead \& Boucher, 2003; Giere, 2008; Fonseca et al., 2010;

89 Curini-Galletti et al., 2012; Fonseca et al., 2014; Guardiola et al., 2015; Leray \& Knowlton,

90 2015; Guardiola et al., 2016). These organisms arguably represent the most abundant component

91 amongst benthic metazoans in all marine systems from the intertidal zone to the deep-sea floor

92 (Danovaro \& Fraschetti, 2002; Giere, 2008). A major bottleneck in meiofaunal surveys is related

93 to the time and expertise required for the analyses of distinctive morphological characters. This

94 taxonomic limitation can now be largely overcome with a combination of environmental DNA

95 (eDNA) and next-generation sequencing (NGS) metabarcoding, which offers a rapidly 
96 developing avenue to assess the presence of a broad spectrum of eukaryotic organisms within our

97 oceans (Kelly et al., 2017; Ransome et al., 2017; Stat et al., 2017).

98 Environmental DNA (eDNA) has been defined by Taberlet et al., (2018) as " a complex

99 mixture of genomic DNA from many different organisms found in environmental samples", a

100 definition which includes bulk samples of water, air, sediment, or plankton. eDNA recovered

101 from complex multi-species substrates are often now combined with metabarcoding approaches,

102 defined by Taberlet et al. (2012) as "high-throughput multispecies (or higher-level taxon)

103 identification using the total and typically degraded DNA extracted from an environmental

104 sample". This approach can now provide a cost-effective and rapid assessment of biodiversity

105 localized to individual coral reefs (Stat et al., 2018). Previous studies have focused on a range of

106 organisms, from unicellular eukaryotes (i.e. protists) (De Vargas et al., 2015) to large animals

107 (Bakker et al. 2017), thought to be detected via the capture of DNA fragments or whole cells

108 shed from the target organism. Benthic collection methods (i.e. Autonomous Reef Monitoring

109 Structures; ARMS) combined with metabarcoding using universal primer sets have also proven

110 useful in surveying cryptobenthic biodiversity not revealed by visual techniques (Al-Rshaidat et

111 al., 2016; Pearman et al., 2016; Pearman et al., 2018). ARMS and comparable methods,

112 however, are not without their own taxonomic biases (Ransome et al., 2017), need to be

113 deployed for months to years in order for sufficient animals to settle in the fibrous matrix, and

114 often require taxonomic specialists to identify the larger fraction of organisms (Pearman et al.,

115 2016). A lack of reference DNA sequences for many marine taxa further hinders their

116 identification.

117 In this pilot study, we test whether sampling of marine sediment combined with eDNA

118 metabarcoding using universal 18S rRNA primers can provide reliable information about the 
119 broad spectrum of taxonomic diversity (at the family level) stratified by depth along subtropical 120 coral reefs. Sediment was selected as the biological substrate as ongoing work suggests that it 121 reveals more benthic families compared to seawater sampling (Koziol et al., in press). We also 122 tested whether taxonomic families of interest were specialized to specific depths, with a focus on 123 the classes Anthozoa (phylum Cnidaria) and Demospongiae (phylum Porifera). Anthozoa

124 includes anemones, stony corals, and octocorals, whereas Demospongiae (sponges) encompasses $12581 \%$ of all sponge species (Van Soest et al., 2018). Contrary to popular belief, on tropical and 126 subtropical reefs, sponge diversity can in fact be higher than that of corals (Diaz \& Rützler, 127 2001), although their taxonomy is not yet resolved. Both of these groups play an important role 128 in the functioning of coral reef ecosystems, such as recycling dissolved organic matter (DOM) 129 (Rix et al., 2016). For example, sponges on coral reefs absorb dissolved organic carbon and 130 return it to the reef via particulate detritus, otherwise known as the 'sponge loop' (de Goeij et al., 131 2013).

132 We chose to focus our efforts on the coastal marine ecosystems of Okinawa, Japan, which 133 are recognized for their high levels of biodiversity and endemism (Roberts et al., 2002). This 134 coastline faces growing anthropogenic pressures due to increased coastal development (Reimer 135 et al., 2015; Heery et al., in review), as well as terrestrial input in the form of pollutants (Ramos, 136 Inoue \& Ohde, 2004; Imo et al., 2008) and nutrient runoff (Shilla et al., 2013). Moreover, the 137 coral reefs of Okinawa have been subject to the effects of climate change, with extreme coral 138 bleaching occurring during the 1998 El Niño-Southern Oscillation (Tsuchiya et al., 2004) and 139 more recently in 2015-2017 (Kayenne et al., 2017; Ministry of the Environment, 2017). Current 140 coral reef biodiversity monitoring efforts in Japan are generally limited to scleractinian corals 141 (i.e. stony corals or hard corals) and fish, and from these data the overall trend for coral reefs in 
142 Okinawa is that of an ecosystem in decline (Hongo \& Yamano, 2013). Here we examine the

143 potential for universal metabarcoding surveys (rapid universal metabarcoding surveys, RUMS)

144 of eDNA in sediment samples to provide snapshots of marine biodiversity that can serve as a

145 baseline to be revisited at future points in time.

146

147 MATERIALS \& METHODS

148 Sampling sites

149 The coral reef sites that we selected were minimally impacted by natural (no freshwater input)

150 and anthropogenic disturbances (no coastal development), although the presence of discarded

151 fishing line at both dive sites suggests some recreational fishing pressure. Cape Hedo (26.87228

$152 \mathrm{~N}, 128.26652^{\circ} \mathrm{E}$ ) is the northernmost point of the main island of Okinawa-jima and is

153 topographically complex, with more than $50 \%$ hard coral cover at shallower sites $(<20 \mathrm{~m})$, and

154 an abundance of sponges and octocorals due to consistently fast currents, which can be seen on

155 the northeast coast (Kudaka et al. 2008). Rukan $\left(26.09961^{\circ} \mathrm{N}, 127.53962^{\circ} \mathrm{E}\right)$ is a small

156 submerged atoll $\sim 10 \mathrm{~km}$ offshore to the southwest of Okinawa-jima, and includes a small lagoon

157 with no land above sea level other than a lighthouse set on concrete blocks. The reef at Rukan is

158 also subject to strong oceanic currents, with a diverse coral community (Ohde and van Woes

159 1999), including large octocorals and sponges on the reef slopes. Both sites are characterized by

160 steep drop-offs with walls greater than $45^{\circ}$ sloping downwards; the Rukan reef wall ends at $\sim 30$

$161 \mathrm{~m}$ depth and levels off into a coral rubble field, whereas the Cape Hedo reef continues to drop

162 down to depths greater than $100 \mathrm{~m}$.

163

164 Sediment collections 
165 Four replicates of approximately $10 \mathrm{~g}$ of marine sediment were collected with sterile $15 \mathrm{ml}$ 166 falcon tubes at $10 \mathrm{~m}, 20 \mathrm{~m}$, and $30 \mathrm{~m}$ depth at two reefs, as well as $40 \mathrm{~m}$ depth at one reef (Cape 167 Hedo) in July 2016 in Okinawa, Japan on SCUBA (Figure 1). The sterile falcon tubes remained 168 closed on the dive until the moment of sampling, and were closed immediately after scooping up 169 the sample; each diver was cautious not to touch the inside of the lid or tube with their own 170 hands, and the diver performing sampling wore gloves. We chose to focus on surface sediment $171(<5 \mathrm{~cm}$ below the substrate) given that their eDNA concentrations can be higher than those in 172 surface seawater (e.g. Torti, Lever \& Jørgensen, 2015) and appear to yield a greater fraction of 173 benthic diversity (Koziol et al., in press). Sediment sampling was repeated at only one of the 174 reefs (Cape Hedo) at $10 \mathrm{~m}, 20 \mathrm{~m}, 30 \mathrm{~m}$, and $40 \mathrm{~m}$ depths in October 2017. Four replicate 175 samples were collected for each site, depth, and year. Sediment samples were placed on ice in a 176 cooler within sterile plastic bags and then frozen at $-20^{\circ} \mathrm{C}$ until processing in a dedicated 177 quarantine and PCR-free DNA extraction laboratory at Curtin University in Perth, Australia. 178

\section{DNA extraction}

180 Total nucleic acids were extracted from each replicate sediment sample following

181 homogenization of $0.5 \mathrm{~g}$ to $0.8 \mathrm{~g}$ of organic material using bead tubes mixed on a Minilys ${ }^{\circledR}$

182 homogenization machine (Bertin Technologies, France). Homogenized replicates were

183 transferred into sterile $2 \mathrm{ml}$ microfuge tubes. Although singly subsampling $\sim 0.5 \mathrm{~g}$ from a much

184 larger volume of sediment (i.e. $\sim 10 \mathrm{ml}$ ) may have missed variance within the sample, grouping 185 of replicates at each site provided confidence in the site-specificity of the community assemblage 186 that we detected with this experimental design. 
Laboratories, CA) following the manufacturer's protocol, with a modification in the reaction

volume of the homogenate to double the default quantity. Purified DNA was then eluted into a

190

final volume of $100 \mu \mathrm{l}$. Four DNA extraction controls were also included in the work flow,

which were processed along with experimental samples in the same manner, save for the absence

of sediment. This kit was chosen because of the advantage of co-purification of inhibitors in 193 sediment samples.

\section{DNA amplification}

A universal primer set targeting 18S rRNA (V1-3 hypervariable region; 18S_uni_1F: 5' -

GCCAGTAGTCATATGCTTGTCT - 3'; 18S_uni_400R: 5' - GCCTGCTGCCTTCCTT - 3';

Pochon et al., 2013) with an amplicon length of $\sim 340-420$ bp was used to maximize the eukaryotic fraction of marine diversity detected along a coral reef depth gradient. Quantitative PCR (qPCR) experiments were set up in a dedicated ultra-clean laboratory at Curtin University designed for ancient DNA work using a QIAgility robotics platform (Qiagen Inc., CA). Given that low copy number and PCR inhibition can severely impact metabarcoding data (Murray,

203 Coghlan \& Bunce, 2015), template input concentrations were optimized using a qPCR dilution 204 series (neat, 1:10, 1:100) based on the reaction conditions described below. To reduce the 205 likelihood of cross-contamination, chimera production, and index-tag jumping (Esling, Lejzerowicz, \& Pawlowski, 2015), amplification of target DNA was performed in a single round of PCR using fusion-tag primers consisting of the 18S primers coupled to Illumina adaptors, custom sequencing primers, and index combinations unique to this study. All qPCR reactions for each replicate were run in duplicate and subsequently pooled to control for amplification 
210 stochasticity. PCR reagents included $1 \times$ AmpliTaq Gold ${ }^{\circledR}$ Buffer (Life Technologies, CA), 2

$211 \mathrm{mM} \mathrm{MgCl}_{2}, 0.25 \mu \mathrm{M}$ dNTPs, $10 \mu \mathrm{g} \mathrm{BSA}, 5$ pmol of each primer, $0.12 \times \mathrm{SYBR} \circledast$ Green (Life

212 Technologies), 1 Unit AmpliTaq Gold DNA polymerase (Life Technologies), $2 \mu$ l of DNA, and

213 Ultrapure $^{\mathrm{TM}}$ Distilled Water (Life Technologies) made up to $25 \mu$ l total volume. PCR was

214 performed on a StepOnePlus Real-Time PCR System (Applied Biosystems, CA, USA) under the 215 following conditions: initial denaturation at $95^{\circ} \mathrm{C}$ for $5 \mathrm{~min}$, followed by 45 cycles of $30 \mathrm{~s}$ at 95 $216{ }^{\circ} \mathrm{C}, 30 \mathrm{~s}$ at $52{ }^{\circ} \mathrm{C}$, and $45 \mathrm{~s}$ at $72{ }^{\circ} \mathrm{C}$, with a final extension for $10 \mathrm{~min}$ at $72^{\circ} \mathrm{C}$.

\section{DNA sequencing}

219 Libraries for sequencing were made by pooling amplicons into equimolar ratios based on qPCR $220 \mathrm{C}_{\mathrm{T}}$ values and the endpoint of amplification curves. Amplicons in each pooled library were size221 selected using a Pippin Prep (Sage Science, MA) and purified using the Qiaquick PCR

222 Purification Kit (Qiagen Inc.). The volume of purified library added to the sequencing run was 223 determined against DNA standards of known molarity on a LabChip GX Touch (PerkinElmer

224 Health Sciences, MA). Final libraries were sequenced paired-end using a 500 cycle MiSeq® V2 225 Reagent Kit and standard flow cell on an Illumina MiSeq platform (Illumina, CA) located in the 226 Trace and Environmental DNA (TrEnD) Laboratory at Curtin University. These samples were 227 included in a mixed run with additional samples from a related study, and therefore did not 228 receive the full output of sequence reads from the standard kit.

\section{Bioinformatic filtering}

231 All sequence data were quality filtered (QF) prior to taxonomic assignment and OTU analysis. 232 Metabarcoding reads recovered by paired-end sequencing were first stitched together using the 
233 Illumina MiSeq Reporter software under the default settings. Sequences were then assigned to 234 samples based on their unique index combinations and trimmed in Geneious ${ }^{\circledR}$ Pro v 4.8.4

235 (Drummond et al., 2009). In order to eliminate low quality sequences, only those with $100 \%$ 236 identity matches to Illumina adaptors, index barcodes, and template specific oligonucleotides

237 were kept for downstream analyses. Sequences were further processed in USEARCH v 9.2 238 (Edgar, 2010). This program was used to trim ambiguous bases, remove sequences with average 239 error rates $>1 \%$, remove sequences $<200$ base pairs, dereplicate each sample, abundance filter

240 unique sequences using both conservative ( $\geq 5$ identical reads) and less conservative $(\geq 2$

241 identical reads) thresholds, and remove chimeras. Given that both the conservative and less

242 conservative QF workflow gave comparable results (raw data available from Dryad Digital

243 Repository XX), we only present data where a minimum of two identical reads are required as a

244 threshold. It should also be noted that the sequences in each replicate were sub-sampled to

24520,000 sequences prior to dereplication to ensure that sampling effort was even among

246 replicates; a random subset of species accumulation curves are included in Supplemental Figure

247 S1. We found that 20,000 sequences struck a balance between the inclusion of samples and the

248 detection of families within each replicate. Despite modest amplification, none of the extraction

249 controls retained sequences following the quality filtering pipeline and are therefore not reported 250 further.

251

\section{Taxonomic assignment}

253 Unique sequences that passed QF were queried against the National Center for Biotechnology

254 Information (NCBI) nucleotide database using BLASTn on the Magnus Cray XC40 system

255 located at the Pawsey Supercomputing Centre in Perth. The BLASTn settings were as follows: - 
256 num_alignments 25; -num_descriptions 25; -reward 1; -qcov_hsp_perc 100; -perc_identity 90.

257 BLASTn results were imported into MEtaGenome ANalyzer (MEGAN) v 5.11.3 (Huson \&

258 Weber, 2013) and taxonomic identities assigned at the family-level based on the lowest common 259 ancestor (LCA) algorithm (minimum bit score $=600$; top percent of reads $=5 \%$; max expected $=$ 260 0.01). Rarefaction analyses were performed in MEGAN (see Supplemental Figure S1) and all 261 taxonomic nomenclature was based on the World Register of Marine Species (Van Soest et al., 262 2017).

263 Given the lack of reference barcodes for many marine taxa, operational taxonomic units 264 (OTUs) were also identified for all QF 18S metabarcoding data assigned to the classes Anthozoa 265 (i.e. anemones, stony corals, soft corals, zoantharians, antipatharians, and naked corals) and 266 Demospongiae (i.e. sponges) in MEGAN using the 'extract reads' function; this provided a 267 taxonomy-independent comparison for these groups that could effectively be aligned. This 268 process followed the MiSeq SOP outlined in Kozich et al. (2013). OTUs were parsed using a $26999 \%$ sequence similarity in Mothur v 1.35.1 (Schloss et al., 2009). A 99\% OTU threshold was 270 used for both classes as this represents a conservative cut-off between different Anthozoa 271 (Shearer et al., 2002; Huang et al., 2008) (but not Ceriantharia; Stampar et al., 2014) and 272 Demospongiae (Redmond et al., 2013; A. Collins pers. comm.) species in order to avoid 273 unnecessarily splitting OTUs. Representative sequences from each OTU were then compared 274 against previously reported GenBank sequences using BLASTn (Altschul et al., 1990) for further 275 identification.

276

\section{Statistical analyses}


278 Family richness was calculated per sample based on the taxonomic composition of marine

279 eukaryotes identified by the $18 \mathrm{~S}$ gene and analysed using the R software package (R Core Team,

280 2016). Kruskal-Wallis tests were used to compare taxonomic richness between depths as data did 281 not meet assumptions of normality.

282 Taxonomic composition of marine eukaryotes at the family-level for $18 \mathrm{~S}$ was analyzed using

283 PRIMER v 7 (Clarke et al., 2014). Data were presence/absence transformed and a Jaccard

284 resemblance matrix was constructed to assess the effect of depth on biological community

285 assemblages. Differences among depths was tested using PERMANOVA (One factor design:

286 Depth [Fixed]) under a reduced model with 9,999 permutations. Pairwise PERMANOVA tests

287 were conducted to compare different depths. Canonical Analysis of Principal coordinates (CAP)

288 was used to visualize differences among categories. Leave-one-out allocation success tests were

289 used to estimate misclassification errors and test the uniqueness of assemblages (Anderson \&

290 Willis, 2003). Plots were overlaid with vectors of the taxa most closely correlated with figure

291 axes (Pearson's correlation value $> \pm 0.4$ ). This entire process was repeated for the combined

292 taxonomy-independent (i.e. OTU) metabarcoding data for classes Anthozoa and Demospongiae.

293

294 RESULTS

295 Using a universal metabarcoding assay targeting the 18S rRNA gene, a total of 3,787,288

296 amplicon reads were sequenced from 42 samples to provide a snapshot of eukaryotic biodiversity

297 along a depth gradient at two coral reefs in Okinawa, Japan (Supplemental Table S1). All 42

298 samples amplified, but two did not pass the QF thresholds for inclusion in the statistical analysis

299 (AWFS_F16_0429, Cape Hedo, 20 m, 2016; SED126, Cape Hedo, 20 m, 2017). The mean

300 number of sequences per sample was 90,174 $\pm 84,764$ SD (Supplemental Table S1). The 
301 metabarcoding data was assigned to 85 eukaryotic classes, 149 orders, and 222 families

302 (Supplemental Table S2). These included a number of reef-forming benthic organisms, including

303 coralline red algae (Class Florideophyceae), polychaete worms (class Polychaeta), tunicates

304 (class Ascidiacea), bivalves (Class Bivalvia), a variety of hexacorals (class Anthozoa),

305 calcareous sponges (class Calcarea), and demosponges (class Demospongiae) (for summary see

306 Figure 2). On average, $440 \pm 223 \mathrm{SD}$ unique sequences were assigned per sample, whereas, on

307 average, $881 \pm 278$ SD unique sequences remained unassigned (Supplemental Table S1), which

308 justified additional downstream taxonomy-independent analyses using OTUs.

309 Taxonomic diversity based on family richness was not significantly different across depths (p

$310=0.79, \mathrm{df}=3, \chi^{2}=1.01 ;$ Figure $\left.3 \mathrm{a}\right)$, but PERMANOVA tests revealed significant differences in

311 marine community assemblages among the different depths $(\mathrm{p}=0.01, \mathrm{df}=3$, pseudo- $\mathrm{F}=1.28)$.

312 The significant differences for depth were between $10 \mathrm{~m}-20 \mathrm{~m}$ and $10 \mathrm{~m}-30 \mathrm{~m}$ (Supplemental

313 Data S1). Based on a Venn diagram, there was modest overlap in families shared between depths 314 compared to families unique to specific depths (Figure 3b).

315 Constrained Canonical Analysis of Principal Coordinates (CAP) analysis supported the

316 notion that there was minimal overlap between marine community assemblages at different

317 depths, from both sites, with the exception of between $20 \mathrm{~m}$ and $30 \mathrm{~m}$ (Figure 4). The allocation

318 success for different depths was $57.5 \%$ overall (Trace statistic: $2.39 ; \mathrm{p}<0.001$ ), with the highest

319 assignment at $10 \mathrm{~m}(72.7 \%)$, followed by $30 \mathrm{~m}(58.3 \%), 40 \mathrm{~m}(50 \%)$, and then $20 \mathrm{~m}(44.4 \%)$.

320 This differential allocation success further confirms the shifts between community assemblages

321 at different depths. Pearson correlations $(r= \pm 0.4)$ indicated that ostracods, nematodes,

322 polychaete worms, fungi, and marine algae and diatoms were the taxa most closely correlated

323 with distinct depths. Green (Chlorellaceae) and red algae (Nemastomataceae) as well as 
324 ostracods (Xestoleberididae) were associated with $10 \mathrm{~m}$, polychaetes (Paraonidae) and diatoms

325 (Rhopalodiaceae, Fragilariaceae) were associated with $20 \mathrm{~m}$ and $30 \mathrm{~m}$, and polychaetes

326 (Pisionidae), nematodes (Oncholaimidae), fungi (Didymellaceae), and chrysophyte algae

327 (Paraphysomonadaceae) were associated with $40 \mathrm{~m}$ (Figure 4).

328 The depth zonation apparent with taxonomy-dependent approaches was supported by the 329 comparison of OTUs across depths within the combined data set including classes Anthozoa and 330 Demospongiae (Figure 5; Supplemental Table S3). PERMANOVA tests indicated significant 331 differences between depths $(\mathrm{p}=0.046, \mathrm{df}=3$, pseudo- $\mathrm{F}=1.3)$. Pearson correlations $(\mathrm{r}= \pm 0.4)$

332 indicated that OTUs from the class Demospongiae (and not Anthozoa) were most closely 333 correlated with different depths (OTU12, OTU27, OTU44, OTU45, and OTU125), suggesting 334 that sponges, and perhaps not anthozoans/corals, may be better indicators of depth given their 335 greater relative read abundance and fine-scale zonation (Figure 5). OTU12 and OTU27, which

336 were correlated with the shallowest depth $(10 \mathrm{~m})$, represent species within Haploscleromorpha 337 clade E and Astrophorina (see Redmond et al. 2013), boring or encrusting and carbonate reef 338 associated sponges, respectively. OTU44, OTU45, and OTU125, on the other hand, which 339 appear to be correlated with $20 \mathrm{~m}$ depth, represent species within Haploscleromorpha clade C 340 (OTU44 and OTU45) and Poecilosclerida (OTU125).

342 DISCUSSION

343 The RUMS eDNA approach utilized in this pilot study may be suited to tracking changes in

344 biodiversity across small spatial and temporal scales, as evidenced by the wide spectrum of

345 biodiversity obtained at each site and the consistent grouping of replicate samples (irrespective 346 of reef or year) by depth (Figures 4 and 5). Previous work has shown that biotic composition 
347 characterized by eDNA differs between depths of 0 and $20 \mathrm{~m}$ or $40 \mathrm{~m}$ in Monterey Bay

348 (Andruszkiewicz et al., 2017), and between sites separated by $75 \mathrm{~m}$ to $4000 \mathrm{~m}$ at the same depth

349 (O'Donnell et al., 2017). Our sediment metabarcoding results demonstrate even finer scale

350 resolution, with notable and significant differences in marine community assemblages at coral

351 reef sites separated by $10 \mathrm{~m}$ depth and less than $240 \mathrm{~m}$ total distance based on a 45 degree reef

352 slope. Collectively, these studies indicate that there are spatial patterns in the organization of

353 eDNA in marine sediments and that it is not homogenous. Based on the null results for the

354 partitioning of beta-diversity (i.e. family richness) among depths (Figure 3A), we suggest that the

355 substitution of species may be due to competition, environmental filtering, or historical events

356 that made the highest relative contribution (also see Pearman et al., 2018) to the fraction of

357 biodiversity that we sequenced. We therefore focus on significant shifts in eukaryotic community

358 assemblages with depth in the remainder of the discussion.

359 Although we detected numerous eukaryotic taxa at the family level with our RUMS, these

360 results likely only reflect a fraction of the total biodiversity present in the immediate

361 environment due to biases introduced by using different sampling substrates (Koziol et al., in

362 press), using a single metabarcoding assay (Stat et al., 2017), and the limited availability of

363 genetic reference sequences (Chain et al., 2017). For example, with regards to metabarcoding

364 assays, recent data suggest that the use of multiple primer sets, as opposed to a single universal

365 PCR assay, can identify a greater richness of marine biodiversity of a given site or sample (Kelly

366 et al., 2017; Stat et al., 2017). Indeed, single DNA marker assays suffer from primer bias (thus

367 excluding entire taxonomic groups), PCR or sequencing artefacts, low taxonomic resolution, and

368 contamination issues (Schloss et al., 2011; Clarke et al., 2014), although the impact of these

369 effects depend on whether you assay and compare relative versus absolute biodiversity. 
Our study, like others, highlights the impact of incomplete reference DNA databases for

371 many marine taxa across loci that are easily targeted by metabarcoding - on average two-thirds

372 of our metabarcodes could not be assigned with fidelity at the family level following quality

373 filtering and querying against NCBI GenBank, the largest open access, annotated collection of

374 nucleotide sequences in the world. This is not surprising given that members of the phyla

375 Nematoda and Platyhelminthes, which make up a significant fraction of the marine biodiversity

376 in sedimentary material, particularly in deep oceanic environments, are often the most poorly

377 characterized genetically (Sinniger et al., 2016). Similarly, the large majority of our

378 Demospongiae 18S sequences matched those vouchered in a single publication (Redmond et al.,

379 2013). Based on this it is clear that more comprehensive DNA sequence reference databases are

380 needed, particularly for understudied or cryptic invertebrate groups. For Anthozoa in particular,

381 it should be noted that we did not detect any Octocorallia within our dataset despite the relative

382 commonality and high diversity of this group on coral reefs in Okinawa (e.g. Lau et al., 2018).

383 There is a relatively large 18S rRNA dataset on GenBank for this group ( $>980$ sequences as of

384 November 26, 2018), and thus we attribute our results to low cellular shedding rates, limitations

385 of the assay, or the fact that these targets are not present in high concentrations in sediment (see

386 Koziol et al., in press). Despite these limitations, the similarities of taxonomy-dependent

387 community assemblages between replicates at the same depth in our study are striking. Although

388 shifts in community assemblages as little as $10 \mathrm{~m}$ apart may initially seem surprising, biotic

389 differences in flora and fauna across small changes in depth are well-known from coral reefs

390 (Friedlander \& Parrish, 1998; Kahng \& Kelley, 2007; Brokovich et al., 2008), and the eDNA in

391 our study reflects such patterns at least to a degree that is statistically significant (Figure 4). 
With these caveats in mind, when time and money are limited, and the goal of the study is a 393 comparison among samples or sites versus identifying the entire marine tree of life in the

394 environment, the extra effort and expenditure may not even be warranted. For example, Stat et al. (2017) demonstrated that PCR assays based on the commonly employed 18S rDNA V4 region detected the greatest proportion of taxa ( $44 \%$ of the total number of families) among the ten total PCR assays examined (also see Kelly et al., 2017). Moreover, RUMS provide information on a subset of benthic organisms or the DNA of planktonic organisms that settle and accumulate in the sediment, and not the entire marine tree of life. Pearman et al. (2018) detected higher biodiversity with multiple primers but showed that similar patterns were found when comparing the two different primer sets. Thus, depending on the goal(s) of the study, expanding to other substrates, assays, or improving the underlying taxonomic assignments may be 403 advantageous.

404 In this study, we attempted to overcome the lack of reference databases by performing 405 additional taxonomic-independent approaches (e.g. OTU analyses) on two important classes or organisms associated with coral reefs, Anthozoa and Demospongiae. These analyses revealed that demosponge DNA was more common in RUMS, and also more helpful in discriminating between depths on a fine-scale (Figure 4). Even with this approach, robust identification of many 409 Demospongiae OTUs to species- or genus-level still remained problematic. Again, this is due to 410 the large amount of taxonomic work that remains to be done in this group (e.g. van Soest et al., 411 2012; Redmond et al., 2013). As a result, our taxonomic assignment of OTUs was limited to 412 large molecular clades at the suborder/order level. An additional limitation is related to specimen 413 discovery; sponges are often cryptic on reefs, and include boring or encrusting species that can 
414 adhere to the undersides of rocks and coral rubble, or live inside the coral carbonate matrix, 415 making post-survey ground-truthing difficult.

416 Our eDNA metabarcoding data was able to generate a set of OTUs that could potentially be 417 used as indicators for different depths. This result is important as it provides targets for future 418 morphological studies and will also help refine metabarcoding assays to better qualify select 419 taxa. In this data, OTUs $12,27,44,45$, and 125 stood out as key discriminating taxa at Cape 420 Hedo and Rukan. OTU12 (unidentified Haploscleromorpha clade E species; sensu Redmond et 421 al., 2013) and OTU27 (Penares sp.), detected in 12.5\% and 5\% of the replicates, respectively, 422 primarily from sediment sampled at $10 \mathrm{~m}$ depth from both sites, represent a mixture of boring or 423 encrusting and carbonate reef associated sponges. These taxonomic groups might therefore be good indicators in coral reef-associated areas. OTU44, OTU45, and OTU125, on the other hand, were based on rare detections (2.5\% of the replicates in each case) at Cape Hedo only at $20 \mathrm{~m}$ depth. Most of these taxa are in groups known from coral reefs in Japan, and Okinawa-jima in particular. Indeed, the taxonomic group corresponding to OTU44 and OTU45 (Haploscleromorpha clade C; sensu Redmond et al., 2013) are a source of manzamines, a polycyclic alkaloid with anti-microbial and anti-leukemic properties that were initially discovered and described from a site on the west coast of Okinawa-jima (Cape Manza; Sakai et 431 al., 1986). OTU125 was an unidentified Poecilosclerida species, with no close matches in 432 GenBank (i.e. closest match cf. Hymedesmia sp., 375 out of 392 bp matching).

\section{CONCLUSIONS}

435 In the context of a rapidly warming ocean and rapid eutrophication of coastal environments, 436 effective biodiversity monitoring is vital to understanding and predicting how the taxonomic 
437 composition of coral reef ecosystems might change. Importantly, these kinds of eDNA data will

438 provide an evidence base to develop appropriate management plans. Given the patterns observed 439 in this data, future RUMS would be well-served to examine even finer scale differences on coral 440 reefs, including expansion of eDNA surveys to other sites and across multiple seasons/years.

441 Taken together, this study adds to a growing body of evidence that eDNA metabarcoding, even

442 in its current state of development, represents a powerful way to explore marine biodiversity

443 across environments. The proportion of RUMS data that remains without taxonomic assignment

444 also brings into focus the need for more complete DNA reference databases underpinned with a 445 robust taxonomy. An integrative framework of eDNA and more classical (morphology-based)

446 taxonomy are needed, in tandem, to characterize marine taxa that sit at the base of the marine

447 food web in coral reef ecosystems.

448

\section{ACKNOWLEDGEMENTS}

450 The authors would like to acknowledge Matthew Power and Megan Coghlan for DNA

451 sequencing assistance. In Okinawa, we thank Yoshihiro Katsushima and the Rukan boat captain

452 for field work assistance, as well as members of the MISE Laboratory at the University of the

453 Ryukyus.

454

455

456

457

458

459 
460

461

462

463

464

465

466

467

468

469

470

471

472

473

474

475

476

477

478

479

480

481

482

483

484

485

486

487

488

489

490

491

492

493

494

495

496

497

498

\section{REFERENCES}

Al-Rshaidat MM, Snider A, Rosebraugh S, Devine AM, Devine TD, Plaisance L, Knowlton N, Leray M (2016) Deep COI sequencing of standardized benthic samples unveils overlooked diversity of Jordanian coral reefs in the northern Red Sea. Genome 59:724-737 DOI: 10.1139/gen-2016-0159.

Altschul SF, Gish W, Miller W, Myers EW, Lipman DJ. 1990. Basic local alignment search tool. Journal of Molecular Biology 215:403-410 DOI: 10.1016/S0022-2836(05)80360-2.

Anderson MJ, Robinson J. 2003. Generalized discriminant analysis based on distances. Australian \& New Zealand Journal of Statistics 45:301-318 DOI: 10.1111/1467-842X.00285.

Anderson MJ, Willis TJ. 2003. Canonical analysis of principal coordinates: A useful method of constrained ordination for ecology. Ecology 84:511-525.

Andruszkiewicz EA, Starks HA, Chavez FP, Sassoubre LM, Block BA, Boehm AB. 2017. Biomonitoring of marine vertebrates in Monterey Bay using eDNA metabarcoding. PloS One 12:e0176343 DOI: 10.1371/journal.pone.0176343.

Bakker J, Wangensteen OS, Chapman DD, Boussarie G, Buddo D, Guttridge TL, Hertler H, Mouillot D, Vigliola L, Mariani S. 2017. Environmental DNA reveals tropical shark diversity in contrasting levels of anthropogenic impact. Scientific Reports 7:16886 DOI: 10.1038/s41598017-17150-2.

Bejarano I, Appeldoorn RS, Nemeth M. 2014. Fishes associated with mesophotic coral ecosystems in La Parguera, Puerto Rico. Coral Reefs 33:313-328 DOI: 10.1007/s00338-0141125-6.

Bongaerts P, Frade PR, Ogier JJ, Hay KB, Van Bleijswijk J, Englebert N, Vermeij MJ, Bak RP, Visser PM, Hoegh-Guldberg O. 2013. Sharing the slope: depth partitioning of agariciid corals and associated Symbiodinium across shallow and mesophotic habitats $(2-60 \mathrm{~m})$ on a Caribbean reef. BMC Evolutionary Biology 13:205 DOI: 10.1186/1471-2148-13-205. 
499 Brokovich E, Einbinder S, Shashar N, Kiflawi M, Kark S. 2008. Descending to the twilight500 zone: changes in coral reef fish assemblages along a depth gradient down to $65 \mathrm{~m}$. Marine

501 Ecology Progress Series 371:253-262 DOI: 10.3354/meps07591.

502

503 Chain FJJ, Brown EA, Maclsaac HJ, Cristescu ME. 2016. Metabarcoding reveals strong spatial 504 structure and temporal turnover of zooplankton communities among marine and freshwater ports.

505 Diversity and Distributions 22:493-504 DOI: 10.1111/ddi.12427.

506

507 Clarke K, Gorley R. 2015. PRIMER v7: User manual/tutorial. Plymouth: PRIMER-E Ltd.

508

509 Curini-Galletti M, Artois T, Delogu V, De Smet WH, Fontaneto D, Jondelius U, Leasi F,

510 Martinez A, Meyer-Wachsmuth I, Nilsson KS, Tongiorgi P. 2012. Patterns of diversity in soft-

511 bodied meiofauna: dispersal ability and body size matter. PLoS One 7:e33801 DOI:

512 10.1371/journal.pone.0033801.

513

514 Danovaro R, Fraschetti S. 2002. Meiofaunal vertical zonation on hard-bottoms: comparison with 515 soft-bottom meiofauna. Marine Ecology Progress Series 230:159-169 DOI:

516 10.3354/meps230159.

517

518 De Goeij JM, Van Oevelen D, Vermeij MJ, Osinga R, Middelburg JJ, de Goeij AF, Admiraal W. 519 2013. Surviving in a marine desert: the sponge loop retains resources within coral reefs. Science 520 342:108-110 DOI: 10.1126/science.1241981.

521

522

523

524

525

526

527

528

529

530

531

532

533

534

535

536

De Vargas C, Audic S, Henry N, Decelle J, Mahé F, Logares R, Lara E, Berney C, Le Bescot N, Probert I, Carmichael M. 2015. Eukaryotic plankton diversity in the sunlit ocean. Science 348:1261605 DOI: 10.1126/science.1261605.

Diaz MC, Rützler K. 2001. Sponges: an essential component of Caribbean coral reefs. Bulletin of Marine Science 69:535-546.

Drummond AJ, Ashton B, Cheung M, Heled J, Kearse M, Moir R, Stones-Havas S, Thierer T, Wilson A. 2009. Geneious v 4.8.4. Available at http://www.geneious.com

Edgar RC. 2010. Search and clustering orders of magnitude faster than BLAST. Bioinformatics 26:2460-61 DOI: 10.1093/bioinformatics/btq461.

537

Esling P, Lejzerowicz F, Pawlowski J. 2015. Accurate multiplexing and filtering for highthroughput amplicon-sequencing. Nucleic Acids Research 43:2513-2524 DOI:

538 
539 Fonseca VG, Carvalho GR, Sung W, Johnson HF, Power DM, Neill SP, Packer M, Blaxter ML,

540 Lambshead PJD, Thomas WK, Creer S. 2010. Second-generation environmental sequencing

541 unmasks marine metazoan biodiversity. Nature Communications 1:98 DOI:

$54210.1038 /$ ncomms 1095 .

543

544 Fonseca VG, Carvalho GR, Nichols B, Quince C, Johnson HF, Neill SP, Lambshead JD, Thomas

545 WK, Power DM, Creer S. 2014. Metagenetic analysis of patterns of distribution and diversity of

546 marine meiobenthic eukaryotes. Global Ecology and Biogeography 23:1293-1302 DOI:

547 10.1111/geb.12223.

548

549 Friedlander AM, Parrish JD. 1998. Habitat characteristics affecting fish assemblages on a

550 Hawaiian coral reef. Journal of Experimental Marine Biology and Ecology 224:1-30 DOI:

551 10.1016/S0022-0981(97)00164-0.

552

553 Gaston KJ. 2000. Global patterns in biodiversity. Nature 405:220-227.

554

555 Giere O. 2008. Meiobenthology: The Microscopic Motile Fauna of Aquatic Sediments. Springer

556 Science \& Business Media.

557

558 Guardiola M, Uriz MJ, Taberlet P, Coissac E, Wangensteen OS, Turon X. 2015. Deep-sea, deep559 sequencing: metabarcoding extracellular DNA from sediments of marine canyons. PLoS One

560 10:e0139633 DOI: 10.1371/journal.pone.0139633.

561

562 Guardiola M, Wangensteen, OS, Taberlet P, Coissac E, Uriz MJ, Turon X. 2016. Spatio-

563 temporal monitoring of deep-sea communities using metabarcoding of sediment DNA and RNA.

564 PeerJ 4:e2807 DOI: 10.7717/peerj.2807.

565

566 Hongo C, Yamano H. 2013. Species-specific responses of corals to bleaching events on

567 anthropogenically turbid reefs on Okinawa Island, Japan, over a 15-year period (1995-2009).

568 PLoS One 8:e60952 DOI: 10.1371/journal.pone.0060952.

569

570 Huang D, Meier R, Todd PA, Chou LM. 2008. Slow mitochondrial COI sequence evolution at

571 the base of the metazoan tree and its implications for DNA barcoding. Journal of Molecular

572 Evolution 66:167-174 DOI: 10.1007/s00239-008-9069-5.

573

574 Huson DH, Weber N. 2013. Microbial community analysis using MEGAN. Methods in

575 Enzymology 531:465-485 DOI: 10.1016/B978-0-12-407863-5.00021-6.

576 
577 Imo ST, Sheikh MA, Sawano K, Fujimura H, Oomori T. 2008. Distribution and possible impacts

578 of toxic organic pollutants on coral reef ecosystems around Okinawa Island, Japan. Pacific

579 Science 62:317-326.

580

581 Kahng SE, Kelley CD. 2007. Vertical zonation of megabenthic taxa on a deep photosynthetic

582 reef (50-140 m) in the Au'au Channel, Hawaii. Coral Reefs 26:679-687 DOI: 10.1007/s00338-

583 007-0253-7.

584

585 Kamezaki M, Higa M, Hirose M, Suda S, Reimer JD. 2013. Different zooxanthellae types in 586 populations of the zoanthid Zoanthus sansibaricus along depth gradients in Okinawa, Japan.

587

588

589

590

591

592

593

594

595

596

597

598

599

600

601

602

603

604

605

606

607

608

609

610

611

612

613

614

615

616

617

618

619 Marine Biodiversity 43:61-70 DOI: 10.1007/s12526-012-0119-2.

Kayanne H, Suzuki R, Liu G. 2017. Bleaching in the Ryukyu Islands in 2016 and associated degree heating week threshold. Galaxea, Journal of Coral Reef Studies 19:17-18 DOI: 10.3755/galaxea.19.1_17.

Kelly RP, Closek CJ, O'Donnell JL, Kralj JE, Shelton AO, Samhouri JF. 2017. Genetic and manual survey methods yield different and complementary views of an ecosystem. Frontiers in Marine Science 3:283 DOI: 10.3389/fmars.2016.00283.

Kozich JJ, Westcott SL, Baxter NT, Highlander SK, Schloss PD. 2013. Development of a dualindex sequencing strategy and curation pipeline for analyzing amplicon sequence data on the MiSeq Illumina sequencing platform. Applied and Environmental Microbiology 79:5112-5120 DOI: 10.1128/AEM.01043-13.

Koziol A, Stat M, Simpson T, Jarman S, DiBattista JD, Harvey E, Marnane M, McDonald J, Bunce M. in press. Environmental DNA metabarcoding studies are critically affected by substrate selection. Molecular Ecology Resources DOI: 10.1111/1755-0998.12971.

Kudaka R, Ono M, Rouf M, Kotler L, Nimi N, Nakaza E. 2008. Sea current and water quality in summer season in Genka Bay of Okinawa. Kaiyo Kaihatsu Ronbunshu 24: 621-625 (in Japanese) DOI: $10.2208 /$ prooe.24.621.

Lambshead PJD, Boucher G. 2003. Marine nematode deep-sea biodiversity-hyperdiverse or hype? Journal of Biogeography 30:475-485 DOI: 10.1046/j.1365-2699.2003.00843.x.

Lau YW, Stokvis FR, van Ofwegen LP, Reimer JD. 2018. Stolonifera from shallow waters in the north-western Pacific: a description of a new genus and two new species within the Arulidae (Anthozoa, Octocorallia). ZooKeys 790:1-19 DOI: 10.3897/zookeys.790.28875

Leray M, Knowlton N. 2015. DNA barcoding and metabarcoding of standardized samples reveal patterns of marine benthic diversity. Proceedings of the National Academy of Sciences of the 620 
621 Lesser MP, Slattery M, Leichter JJ. 2009a. Ecology of mesophotic coral reefs. Journal of

622 Experimental Marine Biology and Ecology 375:1-8 DOI: 10.1016/j.jembe.2009.05.009.

623

624

625

626

627

628

629

630

631

632

633

634

635

636

637

638

639

640

641

642

643

644

645

646

647

648

649

650

651

652

653

654

655

656

657

658

659

660

661

662

663

664

665

666

Lesser MP, Slattery M, Stat M, Ojimi M, Gates RD, Grottoli A. 2009b. Photoacclimitization by the coral Montastraea cavernosa in the mesophotic zone: light, food, and genetics. Ecology 91:990-1003 DOI: 10.1890/09-0313.1.

Menza C, Kendall M, Hile S. 2008. The deeper we go the less we know. Revista de Biología Tropical 56.

Ministry of the Environment. 2017. Iriomote-Ishigaki National Park Survey: results of coral bleaching phenomenon of Sekisei lagoon. http://kyushu.env.go.jp/naha/pre_2017/post_28.html. (in Japanese)

Murray DC, Coghlan ML, Bunce M. 2015. From benchtop to desktop: important considerations when designing amplicon sequencing workflows. PLoS One 10:e0124671 DOI:

10.1371/journal.pone.0124671.

Nir O, Gruber DF, Einbinder S, Kark S, Tchernov D. 2011. Changes in scleractinian coral Seriatopora hystrix morphology and its endocellular Symbiodinium characteristics along a bathymetric gradient from shallow to mesophotic reef. Coral Reefs 30:1089 DOI:

10.1007/s00338-011-0801-z.

O’Donnell JL, Kelly RP, Shelton AO, Samhouri JF, Lowell NC, Williams GD. 2017. Spatial distribution of environmental DNA in a nearshore marine habitat. PeerJ 28:e3044 DOI: 10.7717/peerj.3044.

Ohde S, van Woesik R. 1999. Carbon dioxide flux and metabolic processes of a coral reef, Okinawa. Bulletin of Marine Science 65:559-576.

Pearman JK, Anlauf H, Irigoien X, Carvalho S. 2016. Please mind the gap-Visual census and cryptic biodiversity assessment at central Red Sea coral reefs. Marine Environmental Research 118:20-30 DOI: 10.1016/j.marenvres.2016.04.011.

Pearman JK, Leray M, Villalobos R, Machida RJ, Berumen ML, Knowlton N, Carvalho S. 2018. Cross-shelf investigation of coral reef cryptic benthic organisms reveals diversity patterns of the hidden majority. Scientific Reports 8:8090 DOI: 10.1038/s41598-018-26332-5.

Pochon X, Bott NJ, Smith KF, Wood SA. 2013. Evaluating detection limits of next-generation sequencing for the surveillance and monitoring of international marine pests. PloS One 8:e73935 DOI: $10.1371 /$ journal.pone.0073935.

Ramos AA, Inoue Y, Ohde S. 2004. Metal contents in Porites corals: Anthropogenic input of river run-off into a coral reef from an urbanized area, Okinawa. Marine Pollution Bulletin 48:281-294 DOI: 10.1016/j.marpolbul.2003.08.003. 
667 Ransome E, Geller JB, Timmers M, Leray M, Mahardini A, Sembiring A, Collins AG, Meyer 668 CP. 2017. The importance of standardization for biodiversity comparisons: A case study using 669 autonomous reef monitoring structures (ARMS) and metabarcoding to measure cryptic diversity

670

671

672

673

674

675

676

677

678

679

680

681

682

683

684

685

686

687

688

689

690

691

692

693

694

695

696

697

698

699

700

701

702

703

704

705

706

707

708

709

710

711

712 on Mo'orea coral reefs, French Polynesia. PloS One 12:e175066 DOI:

10.1371/journal.pone.0175066.

Redmond NE, Morrow CC, Thacker RW, Diaz MC, Boury-Esnault N, Cárdenas P, Hajdu E, Lôbo-Hajdu G, Picton BE, Pomponi SA, Kayal E. 2013. Phylogeny and systematics of Demospongiae in light of new small-subunit ribosomal DNA (18S) sequences. Integrative and Comparative Biology 53:388-415 DOI: 10.1093/icb/ict078.

Reimer JD, Yang SY, White KN, Asami R, Fujita K, Hongo C, Ito S, Kawamura I, Maeda I, Mizuyama M, Obuchi M. 2015. Effects of causeway construction on environment and biota of subtropical tidal flats in Okinawa, Japan. Marine Pollution Bulletin 94:153-167 DOI: 10.1016/j.marpolbul.2015.02.037.

Roberts CM, McClean CJ, Veron JE, Hawkins, JP, Allen GR, McAllister DE, Mittermeier CG, Schueler FW, Spalding M, Wells F, Vynne C. 2002. Marine biodiversity hotspots and conservation priorities for tropical reefs. Science 295:1280-1284 DOI: 10.1126/science.1067728.

Rix L, De Goeij JM, Mueller CE, Struck U, Middelburg JJ, Van Duyl FC, Al-Horani FA, Wild C, Naumann MS, Van Oevelen D. 2016. Coral mucus fuels the sponge loop in warm-and coldwater coral reef ecosystems. Scientific Reports 6:18715 DOI: 10.1038/srep18715.

Sakai R, Higa T, Jefford CW, Bernardinelli G. 1986. Manzamine A, a novel antitumor alkaloid from a sponge. Journal of the American Chemical Society 108:6404-6405 DOI:

$10.1021 / \mathrm{ja} 00280 \mathrm{a} 055$.

Schloss PD, Westcott SL, Ryabin T, Hall JR, Hartmann M, Hollister EB, Lesniewski RA, Oakley BB, Parks DH, Robinson CJ, Sahl JW. 2009. Introducing mothur: open-source, platformindependent, community-supported software for describing and comparing microbial communities. Applied and Environmental Microbiology 75:7537-7541 DOI: 10.1128/AEM.01541-09.

Shearer TL, Coffroth MA. 2008. DNA BARCODING: Barcoding corals: limited by interspecific divergence, not intraspecific variation. Molecular Ecology Resources 8:247-55 DOI:

10.1111/j.1471-8286.2007.01996.x.

Shilla DJ, Mimura I, Takagi KK, Tsuchiya M. 2013. Preliminary survey of the nutrient discharge characteristics of Okinawa Rivers, and their potential effects on inshore coral reefs. Galaxea,

Journal of Coral Reef Studies 172-181 DOI: 10.3755/galaxea.15.172.

Sinniger F, Pawlowski J, Harii S, Gooday AJ, Yamamoto H, Chevaldonné P, Cedhagen T, Carvalho G, Creer S. 2016. Worldwide analysis of sedimentary DNA reveals major gaps in taxonomic knowledge of deep-sea benthos. Frontiers in Marine Science 3:92 DOI:

10.3389/fmars.2016.00092. 
713

714

715

716

717

718

719

720

721

722

723

724

725

726

727

728

729

730

731

732

733

734

735

736

737

738

739

740

741

742

743

744

745

746

747

748

749

750

751

752

753

754

755

756

757

758

Slattery M, Lesser MP, Brazeau D, Stokes MD, Leichter JJ. 2011. Connectivity and stability of mesophotic coral reefs. Journal of Experimental Marine Biology and Ecology 408:32-41 DOI: 10.1016/j.jembe.2011.07.024.

Soliman T, Reimer JD, Yang S-Y, Villar-Briones A, Roy MC, Jenke-Kodama H. 2017. Diversity of microbial communities and quantitative chemodiversity in layers of marine sediment cores from a causeway (Kaihu-Doro) in Okinawa Island, Japan. Frontiers in Microbiology 8:2451 DOI: $10.3389 /$ fmicb.2017.02451.

Stampar SN, Maronna MM, Kitahara MV, Reimer JD, Morandini AC. 2014. Fast-evolving mitochondrial DNA in Ceriantharia: a reflection of hexacorallia paraphyly? PLoS One 9:e86612 DOI: $10.1371 /$ journal.pone.0086612.

Stat M, Huggett MJ, Bernasconi R, DiBattista JD, Berry TE, Newman SJ, Harvey ES, Bunce M. 2017. Ecosystem biomonitoring with eDNA: metabarcoding across the tree of life in a tropical marine environment. Scientific Reports 7:12240 DOI: 10.1038/s41598-017-12501-5.

Stat M, John J, DiBattista JD, Newman SJ, Bunce M, Harvey ES. 2018. Combined use of eDNA metabarcoding and video surveillance for the assessment of fish biodiversity. Conservation Biology DOI: 10.1111/cobi.13183.

Sunagawa S, Coelho LP, Chaffron S, Kultima JR, Labadie K, Salazar G, Djahanschiri B, Zeller G, Mende DR, Alberti A, Cornejo-Castillo FM. 2015. Structure and function of the global ocean microbiome. Science 348:1261359 DOI: 10.1126/science.1261359.

Taberlet P, Coissac E, Pompanon F, Brochmann C, Willerslev E. 2012. Towards next-generation biodiversity assessment using DNA metabarcoding. Molecular Ecology 21:2045-2050 DOI: 10.1111/j.1365-294X.2012.05470.x

Taberlet P, Bonin A, Zinger L, Coissac E. 2018. Environmental DNA: For Biodiversity Research and Monitoring. Oxford University Press.

Tittensor DP, Mora C, Jetz W, Lotze HK, Ricard D, Berghe EV, Worm B. 2010. Global patterns and predictors of marine biodiversity across taxa. Nature 466:1098-1101 DOI:

10.1038 /nature09329.

Torti A, Lever MA, Jørgensen BB. 2015. Origin, dynamics, and implications of extracellular DNA pools in marine sediments. Marine Genomics 24:185-196 DOI:

10.1016/j.margen.2015.08.007.

Tsuchiya M, Nadaoka K, Kayanne H, Yamano H. 2004. Coral Reefs of Japan. Tokyo, Ministry of the Environment.

Van Soest RWM, Boury-Esnault N, Hooper JNA, Rützler K, de Voogd NJ, Alvarez B, Hajdu E, Pisera AB, Manconi R, Schönberg C, Klautau M, Picton B, Kelly M, Vacelet J, Dohrmann M, 
759 Díaz M-C, Cárdenas P, Carballo JL, Ríos P, Downey R. 2017. World Porifera database.

760 Available at http://www.marinespecies.org/porifera (accessed 11 December 2017). 
Figure 1

Location and depth of sediment samples collected at two coral reefs in Okinawa, Japan.

Location and depth of sediment samples collected at two coral reefs in Okinawa, Japan.

Photographs provide representative views of the substrate for each location at the minimum and maximum depth sampled. Shaded arrows indicate the direction of depth gradients related to light penetration, nutrients, and water temperature.

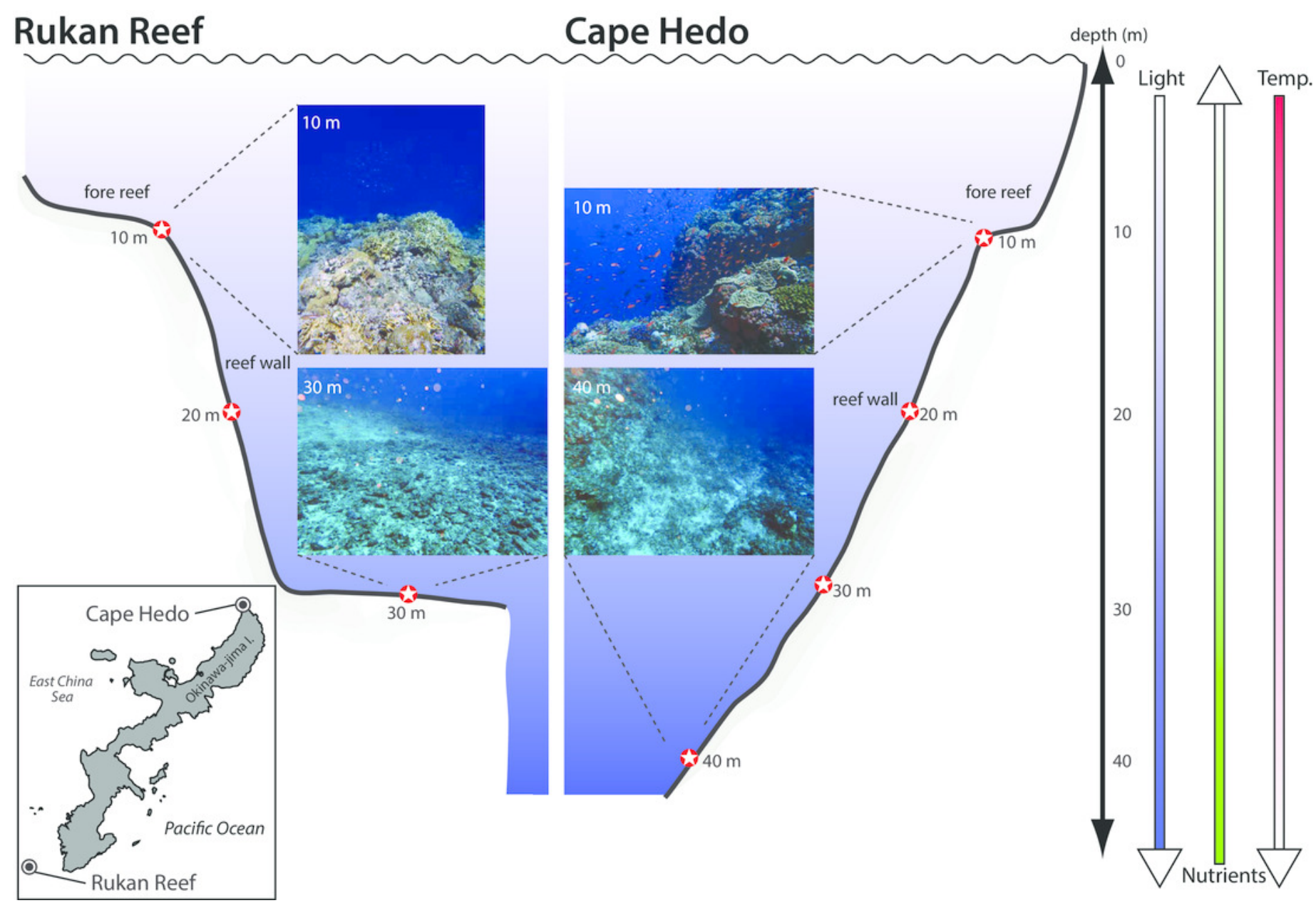




\section{Figure 2}

Taxonomic phylogram of eukaryotic diversity based on sediment samples collected at two coral reefs in Okinawa, Japan and 18S rRNA sequences.

Taxonomic phylogram of eukaryotic diversity based on sediment samples collected at two coral reefs in Okinawa, Japan and 18S rRNA sequences. Pie segments indicate the phyla detected within each kingdom, with the number of families detected within each phyla indicated in parentheses. Color is used only to provide contrast between adjacent pie segments. "Other" represents the number of families in a phyla that make up $<5 \%$ of the total number of families detected in that Kingdom.

A) Animalia ( $\mathrm{N}=103)$

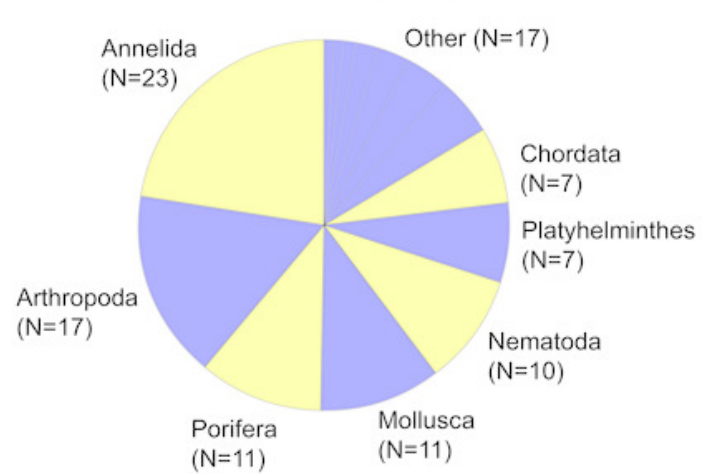

C) Plantae $(\mathrm{N}=25)$

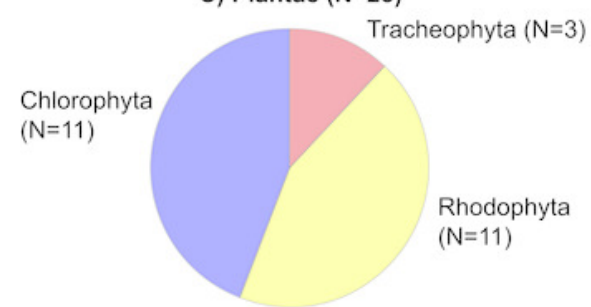

B) Chromista $(\mathrm{N}=81)$

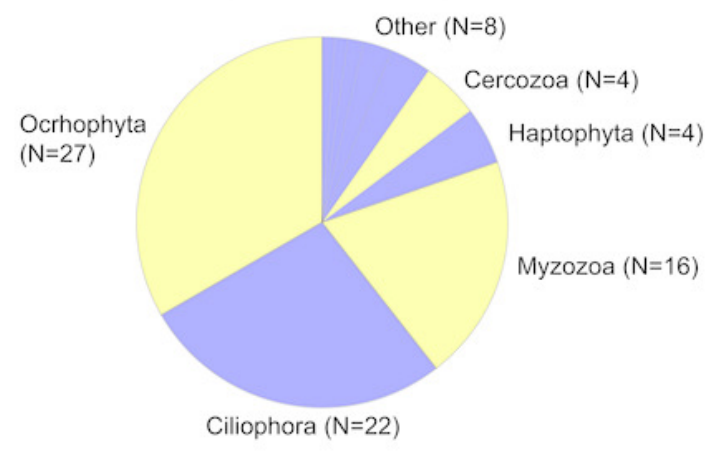

D) Fungi ( $N=8)$

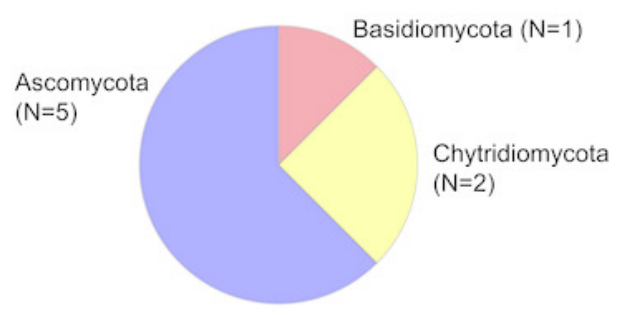

E) Protozoa $(\mathrm{N}=5)$

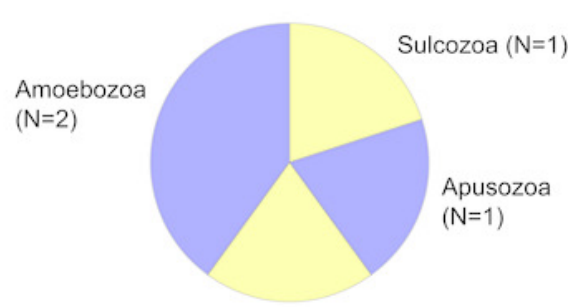

Choanozoa $(\mathrm{N}=1)$ 


\section{Figure 3 (on next page)}

Violin plot representing family richness and Venn diagram representing the number of families identified by depth.

Violin plot representing family richness (a) estimates based on sediment samples collected at two coral reefs in Okinawa, Japan and 185 rRNA sequences. The Venn diagram (b) represents the number of families identified by depth. Yellow, dark blue, red, and light blue segments of the Venn diagram represent the number of families identified at $10 \mathrm{~m}, 20 \mathrm{~m}, 30 \mathrm{~m}$, and 40 $\mathrm{m}$, respectively, with shaded colors indicating the shared number of families across different depths. 
a)

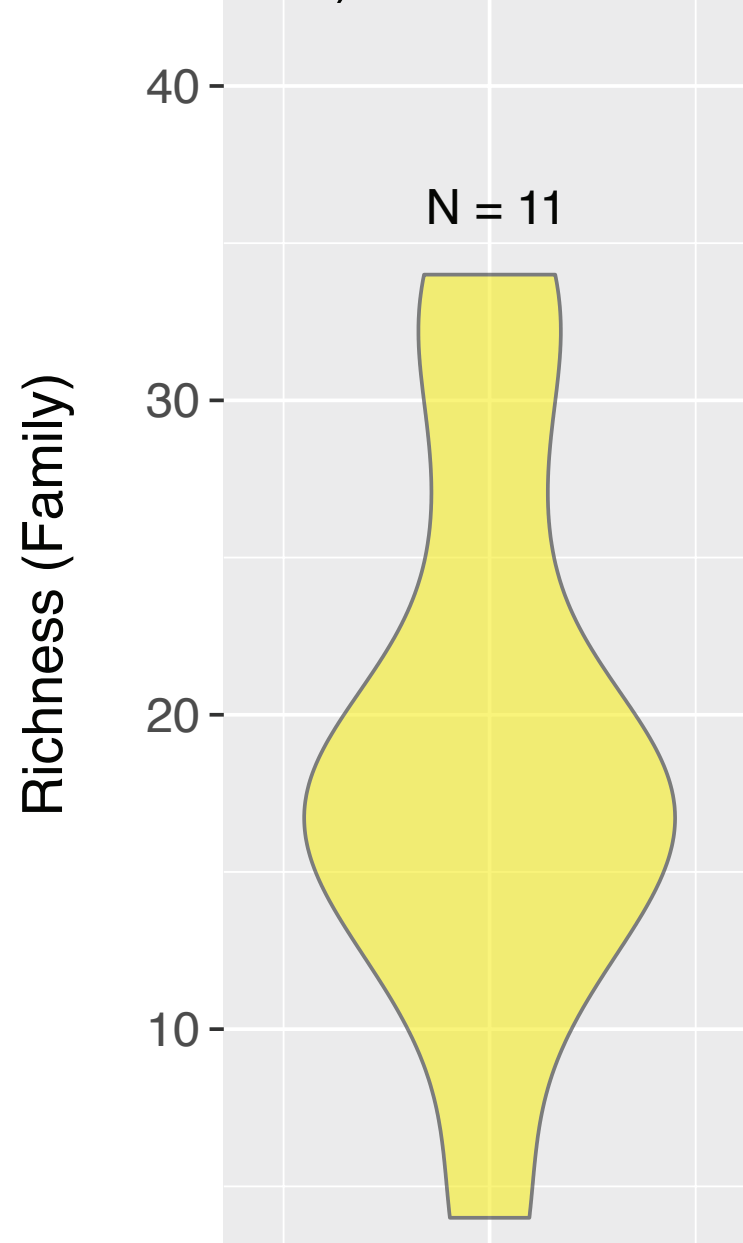

0 -
$\mathrm{N}=12$

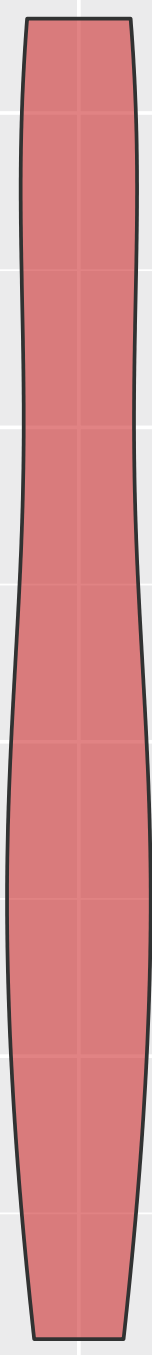

30
$N=8$

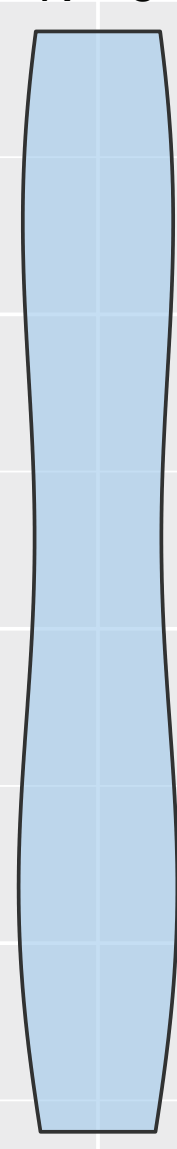

40

20

b)

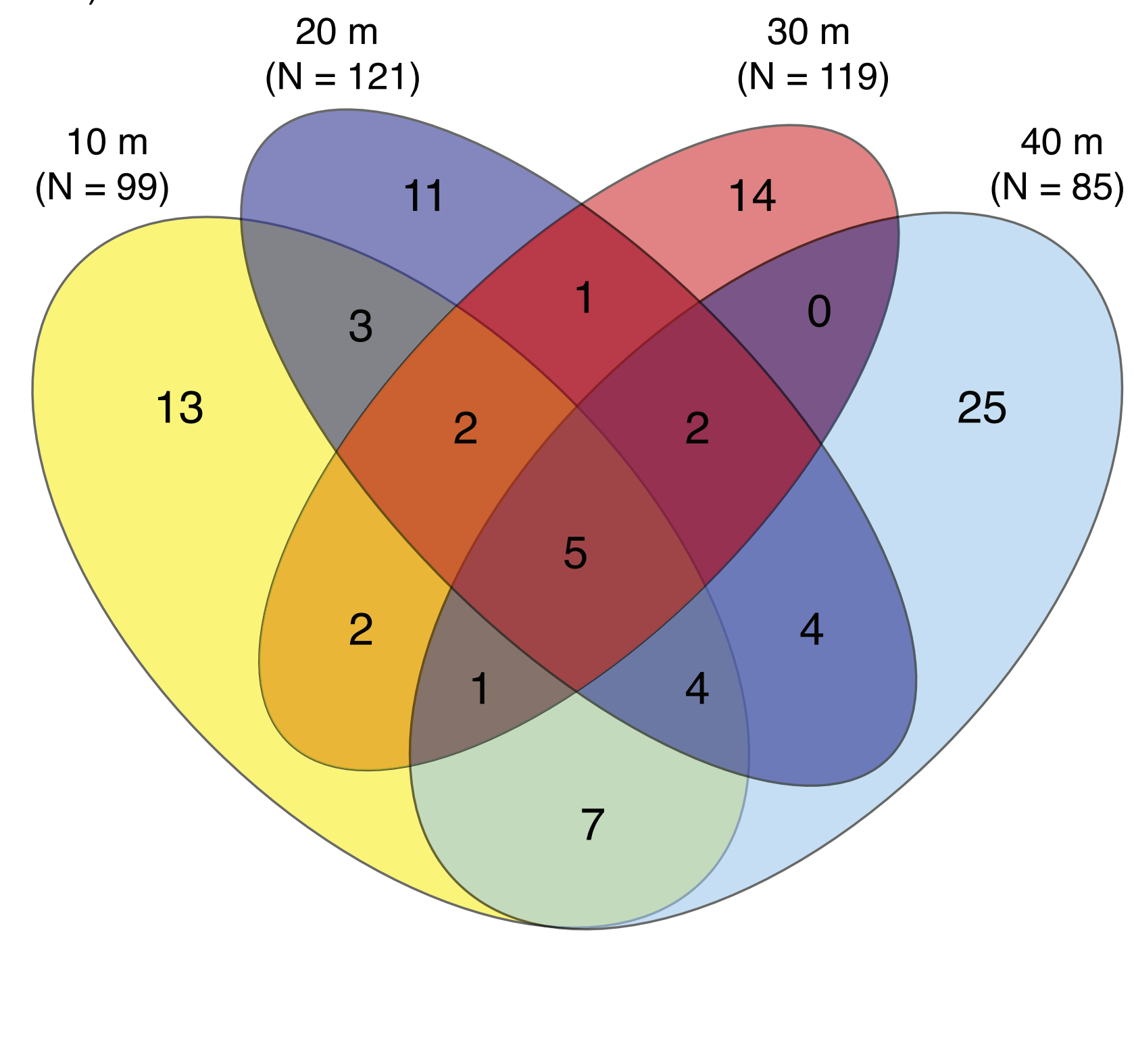


Figure 4(on next page)

Presence/absence of eukaryotic families collected at two coral reefs in Okinawa, Japan.

Constrained Canonical Analysis of Principal Coordinates (CAP) comparing presence/absence of eukaryotic families detected based on sediment samples collected at two coral reefs in Okinawa, Japan and 18S rRNA sequences. The relationship of eukaryotic community assemblages identified in each sample using a Jaccard resemblance matrix for the factor "depth" is shown, with different depths indicated by colors in the legend. Pearson correlation vectors $(r>0.4)$ represent the eukaryotic taxa driving the relationship among samples. 


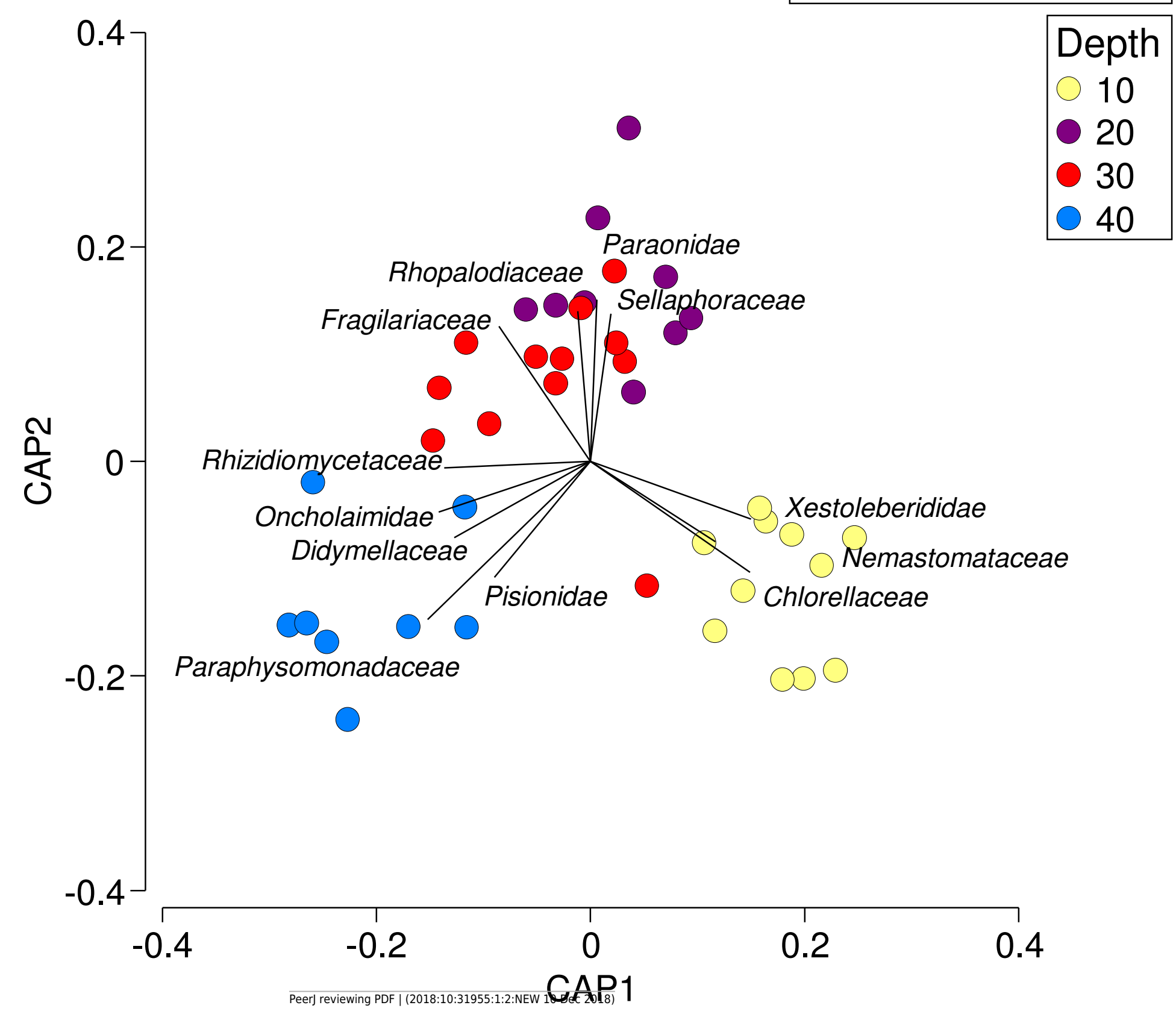


Figure $\mathbf{5}$ (on next page)

Presence/absence of the combined OTU dataset for class Anthozoan and Demospongiaecollected at two coral reefs in Okinawa, Japan.

Canonical Analysis of Principle Coordinates (CAP) ordination plot of the presence/absence of the combined OTU dataset for class Anthozoan and Demospongiae based on sediment samples collected at two coral reefs in Okinawa, Japan and 18S rRNA sequences. The relationship of OTUs identified in each sample using a Jaccard resemblance matrix for factor "depth" is shown, with different depths indicated by colors in the legend. Pearson correlation vectors $(r>+0.4)$ represent the OTUs driving the relationship among samples; all of these OTUs are from the class Demospongiae. 


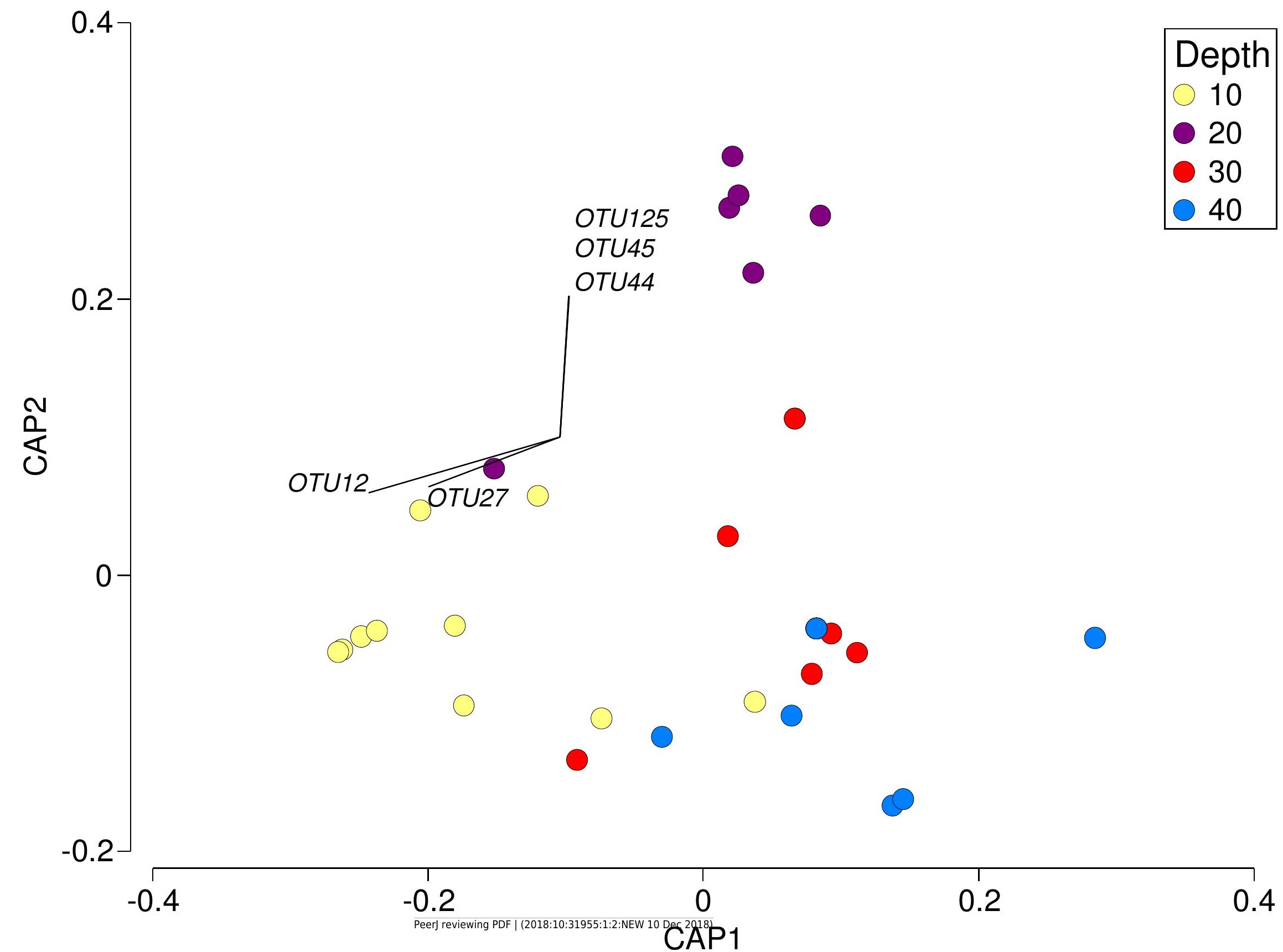

